\title{
CORRELAÇÃO ENTRE DESCONTINUIDADE TÓPICA E ALTERNÂNCIA DE TIPOS TEXTUAIS EM PROGRAMAS DE ENTREVISTAS E DEBATES
}

\author{
PAULO DE TARSO GALEMBECK \\ (UEL)
}

\begin{abstract}
This work discusses the correlation between the rupture of the on-going topic and the alternation of textual types. My starting point is both the current concept of topic ("something people talk about") and the concept of textual types defined by Travaglia (1991), which are, narration, dissertation, injunction and description.
\end{abstract}

\section{INTRODUÇÃO}

Este trabalho discute a correlação entre a ruptura do tópico em andamento e alternância de tipos textuais. Parte-se da noção corrente de tópico ("aquilo acerca de que se está falando") e dos tipos textuais definidos por Travaglia (1991), quais sejam, a narração, a dissertação, a injunção, a descrição.

O córpus do trabalho é constituído por duas edições do programa "Roda Viva" (RV-1: entrevista com a filósofa Marilena Chauí; RV-2: entrevista com o senador Pedro Simon) e duas do "Brasil pensa" (BP-1: debate acerca de mudanças climáticas e o fenômeno "El Niño"; BP2: debate a respeito de segurança global). Os participantes, nos exemplos, são identificados pelo papel previamente estabelecido: M-mediador; E-entrevistado: D-debatedor.

O trabalho compõe-se de duas partes: na primeira, dedicada à fundamentação teórica, são expostas as noções de texto e discurso e são discutidas a tipologia de textos e a formação dos tipos textuais. Na segunda parte, efetua-se a análise dos dados.

\section{FUNDAMENTAÇÃO TEÓRICA}

\subsection{Texto e discurso}

Em sua tese de doutorado, Travaglia (1991) diferencia as Teorias do Texto da Linguiística Textual e utiliza a primeira denominação para o conjunto de contribuições das diferentes disciplinas envolvidas na compreensão da coerência, reservando, para as contribuições específicas da Lingüística, o nome Lingüística Textual. Esta, conforme nos diz o Autor, tem sido entendida como "o estudo dos processos e regularidades gerais e específicos segundo os quais se produz, constitui, compreende e descreve o fenômeno texto", tendo como tarefas básicas a determinação dos princípios de constituição e fatores responsáveis pela coerência do texto, assim como o levantamento de critérios para a delimitação dos textos. A Linguiística 
GALEMBECK - Correlação entre descontinuidade tópica...

Textual focaliza, portanto, o texto, entendido como unidade lingüística concreta (Travaglia, 1991:22).

No plano discursivo, tem-se a Teoria do Discurso, que é a "teoria da determinação histórica dos processos semânticos", os quais são realizados por meio do discurso. Portanto, é o discurso qualquer atividade produtora de efeitos de sentido entre os interlocutores, ou seja, a atividade comunicativa e seu processo de enunciação.

Para o Autor, entre o texto - unidade lingüística concreta - e o discurso - atividade produtora de efeitos de sentido que sedimenta regularidades - existe uma relação dialética, uma vez que "o discurso se realiza em texto e não há texto sem discurso" (Travaglia, 1991:21). O componente discursivo determina o lingüístico, mas cabe às regularidades formar a condiçãobase e as possibilidades para a produção do discurso. É nesse sentido que Koch, em seu livro Argumentação e Linguagem, diz que "o discurso constitui uma unidade pragmática, atividade capaz de produzir efeitos, reações, ou, como diz Benveniste, a língua assumida como exercício pelo indivíduo" (Koch, 2000:21).

Acerca dessa inter-relação, Bakhtin defende a necessidade de se haver, nos estudos lingüísticos, uma concepção clara da natureza do enunciado ${ }^{1}$ (em geral e seus tipos particulares), sem a qual o estudo se tornaria formal e abstrato, pois o enunciado situa-se no cruzamento entre a língua e a vida. Em suas palavras "a língua penetra na vida por meio dos enunciados concretos que a realizam, e é também por meio dos enunciados concretos que a vida penetra na língua". Lembre-se que, para Bakhtin, o homem é visto enquanto produtor de textos, ou seja, constrói-se na e pela linguagem, de forma dialógica (Bakhtin, 1992:282).

Dessa forma, deve-se avaliar o texto como unidade complexa de sentido, no qual se materializam as formações discursivas ${ }^{2}$, possibilitando a existência de tipos de textos, conforme discutiremos a seguir.

\subsection{Formação de tipos textuais}

As idéias e estudos desenvolvidos tanto pelas teorias de texto, quanto pelas teorias de discurso, anteriormente discutidas, levam à concepção de que há formas recorrentes na língua, e os falantes as utilizam na produção verbal. Observou-se anteriormente a existência de uma determinação mútua entre texto e discurso. É justamente esta interdeterminação a condição para a existência de tipos textuais e discursivos.

Bakhtin explica que a língua é utilizada em todas as esferas da atividade humana para a produção de enunciados. Nestes, encontram-se refletidas - no conteúdo, no estilo e sobretudo na construção composicional - as condições específicas e finalidades de cada esfera, as quais vão elaborando, dessa forma, seus tipos relativamente estáveis de enunciados, denominados pelo Autor de gêneros do discurso.

Nessa concepção, o Autor coloca uma distinção essencial entre os gêneros primários, ou simples e os gêneros secundários, ou complexos. Os primeiros são aqueles constituídos em circunstancias de comunicação verbal espontânea e, razão pela qual são marcadas pela relação imediata com a realidade. Em contrapartida, os gêneros secundários perdem essa

\footnotetext{
${ }^{1}$ Bakhtin define o enunciado como sendo a unidade real da comunicação verbal. Equivale, portanto, ao que estamos chamando de texto.

${ }^{2}$ Em relação à Teoria do Discurso, por esta não ser a nossa área de pesquisa, restringimo-nos às concepções aqui discutidas e, desse modo, o emprego destes termos fará referência a tais idéias. Caso seja necessário o uso de novas noções, elas serão explicadas no momento oportuno.
} 
característica, pois sua constituição é mais complexa, eles absorvem e transmutam os gêneros primários, principalmente por meio da escrita.

O presente estudo, por ser relativo à língua falada, volta-se a um gênero primário, sendo de extrema importância a consideração do processo interacional em que os textos foram produzidos.

Travaglia, talvez devido à finalidade de seu estudo, é mais específico e sistemático no que tange aos tipos de texto. Ao tratar das regularidades antes mencionadas, salienta a regularidade lingüística, entendendo-a como "uma cristalização, uma sedimentação que representa o produto (sócio-histórico) de um processo discursivo caracterizado por sua exposição ao acontecimento da enunciação". Os tipos, para o Autor, são exatamente essas cristalizações, assim, eles "sobredeterminam o funcionamento discursivo, determinado as marcas lingüísticas que estarão presentes no texto" (Travaglia, 1991:27 e 31). Os tipos são, ao mesmo tempo, modelo e atividade, e, assim, são parte das condições de produção do discurso. O Autor acrescenta, a esse respeito, que o ato de dizer é sempre tipificante.

\subsection{Estabelecimento de tipologias}

$\mathrm{O}$ ato de dizer é sempre tipificante e o tipo textual, por seu turno, constitui uma atividade estruturante. Nesse sentido, Travaglia (1991) afirma ser a tipologia necessária e importante, pois este princípio organizador possibilita a sistematização e, por conseguinte, a análise. Desse modo, a tipologia direciona a análise, devendo, portanto, ser determinada pelo objeto da análise em relação à natureza do texto.

De acordo com essa perspectiva, os critérios utilizados para o estabelecimento de tipologias revelam não somente a concepção de linguagem e de discurso, como também o tipo de texto considerado. Vilela e Koch (2000:539-40) lembram a impossibilidade de haver tipologias construídas por meio de critérios simultaneamente homogêneos e exaustivos, observando a existência de três linhas gerais nas tipologias de texto:

- as que levam em consideração as características textuais internas do texto;

- as que consideram os traços textuais exteriores ao texto;

- as que combinam os traços internos e os traços externos.

Essa pesquisa filia-se à terceira linha, conforme é possível depreender orientação teórica adotada até o momento.

Resta ainda um outro ponto a ser observado: o fato de a classificação dos textos se dar em termos de dominância ou predomínio de certo tipo de texto sobre os demais tipos presentes no texto, motivo pelo qual o senso comum afirma que não existem textos "puros". Cabe lembrar, a esse respeito, a opinião de Travaglia, que propõe serem puros os tipos de discurso, enquanto os textos raramente são puros em termos de tipos. O citado Autor explica que isto acontece pelo fato dos textos "se organizarem quase sempre a partir do cruzamento, da articulação de vários discursos (vale dizer, de vários tipos de discurso)” (Travaglia, 1991:43).

\subsection{Tipologia de textos}

Neste estudo, são definidos como tipos de textos as diferentes formas de apreender a realidade e apresentar diferentes componentes da mesma. 
GALEMBECK - Correlação entre descontinuidade tópica...

Conforme foi explicitado, a tipologia adotada nesta pesquisa foi sugerida pelos estudos de Travaglia (op. cit.), sendo os tipos textuais propostos pelo Autor definidos em termos de composição. São eles: a narração (exposição de fatos e acontecimentos); a descrição (exposição das características de objetos e seres); dissertação (discussão de conceitos ou exposição de pontos de vista); injunção (pedido ou solicitação, formulados implícita ou explicitamente).

Foi dito, anteriormente, que os tipos são definidos como uma forma de apreender e apresentar a realidade. À medida que isso acontece, vão sendo estabelecidas relações, assim, Travaglia discrimina as relações dos tipos propostos como modo de enunciação, o objetivo da enunciação e a visão que se faz do interlocutor.

Com referência à caracterização desses tipos de textos, o Autor acrescenta ainda que a narração e a injunção são essencialmente discursos do fazer (ações) e do conhecer (fatos, fenômenos), enquanto que a descrição e a dissertação são essencialmente discursos do ser e estar e discursos do ser, respectivamente, embora possam conter ações, fatos ou fenômenos (que não os caracterizam).

\section{ANÁLISE DOS DADOS}

\subsection{Tipos textuais no córpus}

Como este trabalho discute a relação entre o conteúdo ou assunto e os tipos textuais, cabe verificar, inicialmente, que os quatro programas que constituem o córpus deste trabalho, incluemse no tipo dissertativo e opinativo: no "Roda Viva", os entrevistados são instados a manifestar opiniões e juízos acerca de temas polêmicos, introduzidos pelos demais participantes, ao passo que no "Brasil pensa" os temas são controversos e, por si sós, já despertam opiniões contraditórias. Por isso mesmo, considerar-se-á, neste trabalho, apenas os casos em que ocorre a transição do tipo dissertativo (ou, mais raramente, do injuntivo) para os tipos descritivo e narrativo.

Existe, pois, uma vinculação entre assunto e tipo textual e, na fundamentação teórica deste texto, já foram apresentadas duas teorias para a explicação desse fenômeno: as Teorias do Texto e as Teorias do Discurso. As primeiras explicam a organização dos conhecimentos na memória, em blocos, enquanto as segundas procuram examinar o processo de cristalização das formas. Cabe lembrar, a esse respeito, que os modelos cognitivos globais têm, entre outras funções, aquela de representar cognitivamente a estrutura dos diferentes textos, por meio das informações agrupadas nos mesmos, e eles os responsáveis, portanto, pelas orientações textuais nas quais o falante se baseia para expressar suas idéias. A construção textual do tipo entrevista, nesta perspectiva, seria um desses modelos, caracterizada pela estrutura pergunta-resposta, distribuídas para um entrevistador e um entrevistado, respectivamente. De fato, esta estrutura foi mantida na maior parte dos dados analisados.

\subsection{Modalidades de transições tipológicas}

Na sequiência do trabalho, serão apresentadas as modalidades de transições tipológicas e as causas dessas transições.

Nos quatro programas que constituem o córpus deste trabalho, o tipo textual predominante é o dissertativo. Por isso mesmo, a maior parte dos casos de transição tipológica associada à 
mudança corresponde à passagem de um segmento dissertativo para um trecho descritivo ou narrativo:

(1) E: o ensino de Filosofia... no ciclo... colegial... não... não deve visar apenas... o conhecimento de... obras de autores... mas... deve estar voltado... para... deve levar o aluno a refletir sobre o mundo... em que vive... sobre... suas relações... sobre si mesmo... num colégio... vários alunos... me falaram que... que estavam lendo melhor... jornal... estavam... compreendendo os assuntos... passaram a ter interesse... pela... informação (RV-1)

(2) D1: (...) o poder dos Estados Unidos... não é só militar... é também... político e econômico...

D1: mas o que sustenta... assegura... os outros poderes... são as forças militares... são os porta-aviões são os marines... é uma força de intervenção... admirável... equipada com os mais... com o que há de mais... moderno

(BP-2)

Nos dois exemplos anteriores, existe uma mudança de subtópico (ex. 5, dos objetivos do ensino de filosofia, para a alusão a um caso particular; ex. 6, do poder global dos Estados Unidos para o poder militar) vem acompanhada da mudança de tipo textual, ou seja, passa-se de dissertação para, respectivamente, narração e descrição. Essa mudança não é aleatória, pois está ligada à necessidade de contextualizar os dados pela alusão a casos concretos e particulares. Com essa referência, o falante procura demonstrar que está participando ativamente da discussão e, ademais, está engajado no desenvolvimento do tema proposto.

No exemplo a seguir, ocorre a transição entre injunção e descrição, pois o informante julga oportuno retomar um assunto que, no seu entendimento, ainda está pendente, e necessita de esclarecimentos adicionais:

(3) D: senador... o senhor participou do plano... das discussões sobre o plano real... o senhor poderia explicar... como foi... a transição... como:.: se planejou... a mudança?

eu preciso antes voltar.. ao episódio do ministro $R$.... e R.... é uma pessoa boa... e pura... é um homem... de GRANde espiritualidade... e ele teve a coragem de... de confessar.. “como pude ser tão... tão vaidoso" (...)

(RV-2)

Neste exemplo, ocorre o fenômeno da despreferência, caracterizado pela quebra das expectativas em relação ao que foi solicitado.

A tabela a seguir mostra o número de ocorrências de transições tipológicas associadas a mudanças de tópico:

Tabela I - Transições tipológicas e mudanças de tópico.

\begin{tabular}{|l|c|c|c|}
\hline & D/N-D & I/N-D & $\mathbf{N}^{\mathbf{0}}$ de SbTs \\
\hline RV-1 & 05 & 01 & 38 \\
\hline RV-2 & 06 & 01 & 36 \\
\hline BP-1 & 03 & - & 19 \\
\hline BP-2 & 02 & 02 & 17 \\
\hline
\end{tabular}


GALEMBECK - Correlação entre descontinuidade tópica...

Nos inquéritos que constituem o córpus deste trabalho, é baixa a freqüência de transições tipológicas associadas à mudanças tópicas. Esse baixo índice de ocorrência é devido ao fato de predominar, nos citados inquéritos, o tipo dissertativo. Os fragmentos de tipo descritivo ou narrativo, aliás, correspondem a momentos específicos, nos quais o locutor sente a necessidade de introduzir informações ou esclarecimentos adicionais, como forma de contextualizar os assuntos tratados ou inseri-los no universo sociocognitivo dos interlocutores.

\subsection{Causas das transições tipológicas}

As causas mais freqüentes de transições tipológicas associadas a mudanças de tópico são representadas por um pedido ou solicitação explícita de um participante, pela introdução de novo tópico ou retomada de tópico anterior, ou, ainda, pela necessidade de o documentador explicitar ou contextualizar as próprias palavras. Essas causas correspondem a $86 \%$ das ocorrências e seu predomínio deve-se ao fato de serem elas as razões que mais de perto se associam ao desenvolvimento tópico.

Além disso, o predomínio dessas três causas decorre do dinamismo dos programas: em princípio, caberia ao mediador introduzir os temas e dirigir a interação, ao passo que o entrevistado e os debatedores deveriam desenvolver os temas. Ocorre, porém, que a interação é cruzada, ou seja, os debatedores (e, por vezes, também o próprio entrevistado) formulam perguntas entre si e, ademais, o próprio mediador assume o papel de debatedor. Em suma, o predomínio das causas mencionadas decorre do dinamismo da interação falada e do fato de programas estarem fortemente centrados no desenvolvimento de um tópico pré-determinado.

Cada uma das causas será explicitada a seguir:

(4) E: (...) então... foi no... no Colégio... Presidente Roosevelt... que eu passei a me interessar por... por Filosofia... tive... bons professores... de Filosofia... e Literatura... que ensinavam a pensar.. que encaminhava, o aluno para reflexão... e, não... não reduziam essas duas matérias... a Filosofia... e a Literatura... a uma lista... de autores e de li/ de obras...

D: era um colégio público?

E: era colégio público... estadual...

D: e como era o ensino público... nessa época?...

E: era um ensino... de qualidade... boas:.... boas instalações... bons professores... os alunos selecionados... por um exame... de admissão... mas... eram poucas escolas... geralmente... nos:: bairros:: mais próximos... do Centro...

$(\mathrm{RV}-1)$

A entrevistada estava, relatando como havia se manifestado o seu interesse pela Filosofia, quando um dos entrevistadores solicita a ela que caracterize o ensino público da época. Ao fazê-lo, a entrevistada dá início a um fragmento digressivo, com o qual ela procura enfatizar as boas qualidades das escolas públicas da época, e a necessidade de resgatar a qualidade dessas escolas. Há, pois, uma alternância de tipo textual associada à mudança de tópico, e ela flui do próprio dinamismo do texto falado.

No exemplo a seguir, verifica-se a sobreposição de duas causas, a solicitação de um participante e a alusão a um trecho anterior: 
Cadernos de Estudos Lingüísticos 48(1) - Jan./Jun. 2006

(5) E: (...) no caso do Collor... no afastamento... impeachment... ficou clara a capacidade de mobilização do povo... dos caras-pintadas... como já tinha... tinha sido.: vista..... no caso das Diretas-já... por isso... nenhum governo... pode governar sem o povo...

D: Senador... o senhor disse que o Rio Grande foi o estado... mais atingido pelos militares... o senhor poderia... explicar... como assim?

$\mathrm{E}$ : o que aconteceu... no resto do Brasil... no Rio Grande... deve ser multiplicado... por dez... foi o estado... em que a Assembléia ficou mais tempo... fechada... foi... foi... o estado... em que a oposição era:.... mais forte... então cassaram:.... foram cassados deputados... para ARENA... poder... ganhar.. proibiram os candidatos... de um partido... de votar no outro... deputa::dos...

D: [senador..

E: da ARENA não puderam votar.. no MDB... houve muitos prefeitos... cassados... perseguidos (...)

(RV-2)

A alternância entre um texto dissertativo e um narrativo ocorre devido à solicitação do debatedor, que remete a um trecho anterior da entrevista.

(6) M: (...) vamos comentar os fenômenos climáticos e como eles afetam o nosso país...

D: vou retomar o El Niño... porque é preciso caracterizar bem o fenômeno

D: o El Niño é um fenômeno natural... eu vou tentar em breves palavras dizer o que que é o El Niño... o El Niño existe há milhares de anos... ou muito... ou muito mais (...) o El Niño (você) pode interpretar.. de uma maneira muito simples pensando... que nós temos uma eNORme... gigantesca piscina... e que a água é quente de um lado da piscina... que é o lado... da Indonésia da Austrália no Oceano Pacífico... e... (o) lado de cá da América do Sul do Peru do Equador a água fria... e o que mantém essa separação das águas... quentes das águas frias... é um vento muito forte... os ventos alísios... que sopram... da América do Sul pra Austrália... se num dado momento alguém desliga esse ventilador... as águas quentes... vão refluir... e chegar até a América do Sul... em linhas gerais

É isso que (é) o El Niño (...)

(BP-1)

O texto injuntivo produzido pelo mediador, que constitui uma solicitação implícita, é seguido por texto descritivo, no qual um dos debatedores caracteriza o El Niño. Não há uma solicitação explícita e a retomada do tópico anterior serve para demonstrar que o debatedor conhece o assunto e participa ativamente da construção do tópico.

(c) Necessidade de contextualização.

Em certas passagens, verifica-se que o falante sente a necessidade de explicitar ou contextualizar os assuntos tratados e o faz com um breve relato ou uma descrição.

(7) (Os participantes discutem o poder global dos Estados Unidos.)

D: nós estamos discutindo... o:.... o poderio dos Estados Unidos... em duas... duas áreas... econômico... político... mas não podemos esquecer que... que essas áreas... são sustentadas... por um forte esquema... militar... vol/dirigido para a intervenção... em áreas 
GALEMBECK - Correlação entre descontinuidade tópica...

nas quais os americanos se sintam... ameaçados... foi essa força... que levou os Estados Unidos... a intervirem no Iraque... no Oriente Médio... na América Central... desde o início... do século XX... uma das marcas... da poli/política externa americana... tem sido a intervenção em áreas... supostamente... estratégicas... vitais... para os interesses dos... Estados... Unidos...

(BP-2)

Os debatedores discutiam as formas do poderio americano, quando um dos participantes lembra uma das facetas desse poderio que ainda não fora mencionada, o poderio militar. Como forma de justificar o que havia dito, ele faz um breve relato das invasões americanas em alguns países. Com esse procedimento, o debatedor indica que está participando ativamente da discussão do assunto e, ademais, procura interagir com os demais participantes e os ouvintes.

\section{COMENTÁRIOS CONCLUSIVOS}

O exame da correlação entre mudança de tópico e alternância de tipo textual nos programas que constituem o córpus deste trabalho revela duas constantes. Inicialmente, há que se notar que a freqüência da citada correlação é baixa, já que predomina o tipo textual dissertativo, tanto na modalidade dissertação expositiva, como na argumentativa. A segunda constante é que a citada correlação ocorre sobretudo nos momentos em que o locutor sente a necessidade de aludir a fatos, pessoas ou situações, como forma de contextualizar o assunto tratado.

A necessidade de contextualização, por sua vez, evidencia que a interação é administrada passo a passo e que as ações dos interlocutores são imprevisíveis, pois o locutor não pode prever as reações dos parceiros, nem estes sabem o que será dito pelo interlocutor.

\section{REFERÊNCIAS BIBLIOGRÁFICAS}

BAKHTIN, M. (1992). Os gêneros do discurso. In: Estética da criação verbal. São Paulo: Martins Fontes, p. 279-326.

KOCH, I. V. (2000). Argumentação e Linguagem. 6. ed. São Paulo; Cortez.

TRAVAGLIA, L. C. (1991). Um estudo textual-discursivo do verbo no português. Campinas: S. C. P., (Tese de doutorado apresentada ao Instituto de Estudos da Linguagem).

. (1996). Tipologia e a coesão/coerência no texto oral: transições tipológicas. In: CASTILHO, A. T. e BASÍLIO, M. (org.). Gramática do português falado V. IV-Estudos descritivos. Campinas: FAPESP/ ED. da UNICAMP, p. 453-471.

VILELA, M. e KOCH, I. V. (2000). Gêneros e sequiências textuais. In: Gramática da Língua Portuguesa. Coimbra: Almedina. 